\section{PO-0594 WHO IS THE RECEPTOR OF DONOR MILK FROM A HOSPITAL MILK BANK?}

${ }^{1}$ MV Jiménez Cabanillas, 'L Serrano López, 'L Zamorano Bonilla, ${ }^{2} E$ Martín Álvarez, ${ }^{2} \mathrm{M}$ Peña Caballero, ${ }^{2} \mathrm{JA}$ Hurtado Suazo. ${ }^{1}$ Paediatrics, Hospital Virgen de Las Nieves, Granada, Spain; ${ }^{2}$ Neonatology, Hospital Virgen de Las Nieves, Granada, Spain

10.1136/archdischild-2014-307384.1235

Objective To analyse if the recipients profile has changed since the implementation of a human milk bank (HMB) in the Neonatal Unit of a tertiary hospital, as well as the clinical indications of donor milk (DM).

Material and methods A descriptive research has been carried out by revising the HMB database from June 2010 to December 2013. The following variables were taken into account: gestational age (GA), birth weight (BW), time of DM reception and reasons for the DM administration.

Results During the researched period, 255 newborn received DM in our centre: 29 (2010), 75 (2011), 84 (2012), 67 (2013). The average GA was 31. BW was 1575 g. Average duration ofintake was 17 days.

Annual stratified analysis: In 2010, the average GA is 31 and the average BW is $1335 \mathrm{~g}$. In 2011, 31 weeks and $1657 \mathrm{~g}$. In 2012, 31 weeks and 1657 g. In 2013, 31 weeks and1688 g.

Prematurity was the main indication for dispensing DM and enteral feeding intolerance is becoming an important indication for DM. In $15 \%$ of recipients in 2013, this was the reason for prescription.

Conclusions According to the present information the main reasons for giving DM have been prematurity and low birth weight (63\% of all recipients were premature babies born before 32 weeks).

The number of children who take advantage of donor milk has increased as the human milk bank has provided higher amounts of DM in our centre. The administering indications for DM have been also increased, outlining the enteral feeding difficulties.

\section{PO-0595 WITHDRAWN}

\section{PO-0596 NEONUTRINET - INTERNATIONAL DATABASE ON NEONATAL NUTRITION IN VERY LOW BIRTH WEIGHT INFANTS}

\begin{abstract}
${ }^{1} Y \mathrm{Li},{ }^{2} \mathrm{M}$ de Waard, ${ }^{3} \mathrm{Y}$ Zhu, ${ }^{1} \mathrm{~A}$ Erichsen, ${ }^{1} \mathrm{~B}$ Andersen, ${ }^{4} \mathrm{~J}$ Mei, ${ }^{5} \mathrm{G}$ Greisen, ${ }^{1} \mathrm{P}$ Sangild, ${ }^{6}$ J van Goudoever, ${ }^{6}$ NeoNutriNet Study Group. ${ }^{1}$ Department of Nutrition Exercise and Sports, University of Copenhagen, Frederiksberg C, Denmark; ${ }^{2}$ Dutch Human Milk Bank, VU University Medical Center, Amsterdam, Netherlands; ${ }^{3}$ Department of Maternal and Child Health, Sun Yat-Sen University, Guangzhou, China; ${ }^{4}$ Department of Neonatology, Shenzhen Women and Children's Hospital, Shenzhen, China; ${ }^{5}$ Department of Neonatology, Copenhagen University Hospital, Copenhagen, Denmark; ${ }^{6}$ Department of Pediatrics, VU University Medical Center, Amsterdam, Netherlands
\end{abstract}

\subsection{6/archdischild-2014-307384.1236}

Background and aims Nutrition for VLBW infants varies widely among countries. To better understand differences in nutritional practices internationally, we compare data from fourteen hospitals from eight countries (Guangzhou, Shenzhen, Foshan, Amsterdam, Auckland, Copenhagen, Chennai, Chicago, Perth, Newcastle).

Methods Infants with birth weights $<1500 \mathrm{~g}$ are included and data include time, type, and amount of (par)enteral nutrition, anti-/pro-biotics, anthropometrics and clinical complications from birth to $37 \mathrm{w}$ corrected gestational age, or discharge.
Results Data collection is ongoing, here preliminary data are reported for two selected hospitals (2011-2012, $\mathrm{n}=96$ $+107=203$ ) with similar demographic data (e.g. birth weight, median 1335 g; gestational age, median $30.1 \mathrm{w}$; gender, 59\% boys). In hospital $\mathrm{A}$, the growth velocity and proportion of infants reaching $120 \mathrm{~mL} / \mathrm{kg} / \mathrm{d}$ enteral feeding at 5 weeks was higher (median 14.5 vs. $9.1 \mathrm{~g} / \mathrm{kg} / \mathrm{d}$ and 84 vs. $69 \%, \mathrm{P}<0.05$ ), and the decrease in weight Z-score was lower vs. B (median 0.55 vs. $-0.94, \mathrm{P}<0.05)$. Neither of the units reached the protein intake recommended by ESPGHAN $(3.5 \mathrm{~g} / \mathrm{kg} / \mathrm{d}$, JPGN, 50, 89-95, 2010) within the first month although the average daily deficit was less in hospital A vs. B (median -0.8 vs. $-1.2 \mathrm{~g} / \mathrm{kg} / \mathrm{d}$, P $<0.05$ ). NEC incidence was lower in hospital A vs. B (1 vs. 9\%, $\mathrm{P}<0.05)$. There was no difference in the time on antibiotics ( $\sim 50 \%$ of hospitalisation days).

Conclusion Large differences in nutrition and growth outcomes were evident between the two units. The NeoNutriNet cohort will show how differences in nutrition may relate to feeding guidelines, clinical traditions, and use of anti-/pro-biotics around the world.

\section{PO-0597 A NATIONWIDE SURVEY OF NEONATAL COW'S MILK ALLERGY IN THE UK}

J Mahadevan, A Gupta, C Harikumar, S Gupta, S Janakiraman. Neonates, University Hospital of North Tees, Stockton - On- Tees, UK

\subsection{6/archdischild-2014-307384.1237}

Background and aims Cow's Milk Allergy (CMA) is one of the most common food allergies in children. It can affect any age including the neonate. There is paucity of literature about its presentation in the newborn period and its management.

The primary objective of this survey was to understand the level of awareness about CMA in Newborns in neonatal units in the UK. Our secondary objective was to estimate the incidence of Cow's Milk Allergy in newborns in the UK.

Methods This was an online survey of neonatologists identified through the BAPM and the Neonatal Networks.

Results 64 responses were received from consultant neonatologists. 42 out of $63(66.7 \%)$ level 3 units responded.

$78 \%$ of the respondents believed that CMA exists in newborn. The number of newborns with CMA diagnosed in the last 2 years was more than 152 . $50 \%$ of these babies were born preterm and at the time of diagnosis, 33\% were still $<37$ weeks. $26 \%$ babies with CMA had birth weight $<1.5 \mathrm{~kg}$.

The most common symptoms of CMA were blood in stool, abdominal distension and diarrhoea. 84\% were diagnosed on clinical features only. Equal proportions of babies were on breast milk and preterm formula at the time of diagnosis.

Conclusions This survey demonstrates a high level of awareness in an otherwise poorly studied area in newborns. It highlights the need for systematic studies to facilitate decision making among clinicians.

\section{PO-0598 THE ECONOMIC IMPACT OF LOW PROTEIN FORMULA FOR THE CHILDREN OF OVERWEIGHT AND OBESE MOTHERS}

${ }^{1} \mathrm{~K}$ Marsh, ${ }^{1} \mathrm{P}$ Orfanos, ${ }^{1} \mathrm{~N}$ Revankar, ${ }^{1} \mathrm{~J}$ Moller, ${ }^{2} \mathrm{P}$ Detzel. ${ }^{1}$ Health Economics and Epidemiology (Modelling and Simulation), Evidera, London, UK; ${ }^{2}$ Health Economics and Medical Affair, Nestlé Nutrition Institute, Geneva, Switzerland

10.1136/archdischild-2014-307384.1238 
Background and aims Global prevalence of obesity has doubled the last 30 years, with WHO estimating that $10 \%$ of men and $14 \%$ of women worldwide are obese. The corresponding health risk is associated with a significant health system cost, loss of health related quality of life, and economic costs such as reduced productivity. Obesity in adulthood is the result of several factors, including weight gain during infanthood. The objective of this paper is to demonstrate the impact on infant weight gain and economic value of low protein nutritional formula compared with standard protein nutritional formula.

Methods A double blind, randomised, controlled trial of 252 healthy infants born of overweight or obese mothers estimated the impact of formula onweight gain up to 36 months. A discrete event simulation estimated the corresponding impact on adult BMI, the incidence of obesity-related diseasesand consequent lifetime changes in health care resources use, health related quality of life (HRQoL), and productivity.

Results Low protein infant formula reduced weight gain at 36 months by $0.31 \mathrm{~kg}$ (from $16.04 \mathrm{~kg}$ with standard formula to $15.74 \mathrm{~kg}$ with low protein formula). The simulation estimates the corresponding changes in the following outcomes over infants' lifetimes: a BMI; incidence of diabetes, stroke, CHD; health care costs, HRQoL and productivity.

Conclusions The use of low protein formula for infants of overweight orobese mothers not only reduces infant weight gain, but also generates lifetime improvements in quality of life, health cost savings and improvements in productivity.

\section{PO-0599 EFFECTS OF NON-NUTRITIVE SUCKING ON GASTROESOPHAGEAL REFLUX IN SYMPTOMATIC PRETERM INFANTS}

L Corvaglia, S Mazzetti, FM Corrado, S Martini, E Mariani, E Legnani, G Faldella. U. O. Neonatologia E Terapia Intensiva Neonatale, Policlinico Sant'Orsola-Malpighi, Bologna, Italy

\subsection{6/archdischild-2014-307384.1239}

Background The therapeutic management of gastroesophageal reflux (GER) in preterm infants still represents a controversial issue among neonatologists. To date, different non-pharmacological strategies, such as body positioning, milk thickening or changes of feeding modalities, have been proposed. However, the effects of non-nutritive sucking (NNS) on GER features, detected by multiple intraluminal impedance (MII), have not yet been evaluated in preterm newborns symptomatic for GER.

Patients and methods Nineteen preterm newborns (GE $\leq 33$ weeks) with GER symptoms underwent a 24-hours pH-MII monitoring. During this period, each infant received eight meals, four followed by NNS, applied by means of pacifier, and four not. Differences in GER features (number of episodes, acidity, duration and height reached) between NNS and non-NNS postprandial periods were evaluated by Wilcoxon signed-rank test.

Results No significant difference in GER features between NNS and non-NNS periods was found. However, postprandial periods without NNS resulted in a slight increase in the mean duration of acid GER episodes (NNS vs. NON-NNS, median values: 51.15 vs. $88.20 \mathrm{sec}, \mathrm{p}$ 0.159). Consequently, during NNS periods the time of esophageal acid exposure was reduced (NNS vs. NON-NNS, median values: 3.54 vs. $6.15 \%, \mathrm{p} 0.171$ ).

Conclusions According to our results, NNS administration during postprandial periods seems to have no significant effects on GER features in symptomatic preterm infants. However, during NNS periods we observed a slight, though not significant,
Abstract P0-0600 Table 1 Influencing factors in unsuccessful breastfeeding first day after delivery

\begin{tabular}{|c|c|c|}
\hline \multicolumn{3}{|l|}{ Factors } \\
\hline & & Epidemiologic \\
\hline Newborn causes & Macro nipple & causes \\
\hline Prematurity & Cosmetic appearance of breast & Age \\
\hline Low birth weight & Drugs & District \\
\hline \multirow[t]{2}{*}{ Oral problem (cleftand lips palate) } & Maternal addiction & Newborn gender \\
\hline & & Sequence \\
\hline Swallowing problem & Maternal stresses & newborn \\
\hline Sleepiness & Cultural causes & Delivery type \\
\hline Unilateral breast suckling & Pacifier usage & \\
\hline Short suckling & Dextrose water feeding & \\
\hline Poor attachment to breast & No belief to colostrums feeding & \\
\hline Maternal causes & Family dispute of parents & \\
\hline Milk insufficiency & Family consults & \\
\hline Inverted nipples & Medical causes & \\
\hline Breast engorgement & Newborn hospitalisation & \\
\hline Nipples fissure & Maternal hospitalisation & \\
\hline Maternal vaginal bleeding & Educational causes & \\
\hline \multicolumn{3}{|c|}{ Breast milk inadequacy thought of } \\
\hline mother & Physiologic delivery training & \\
\hline & Breastfeeding training in room- & \\
\hline Episiotomy pain & ing in & \\
\hline Caesareans section incision pain & Academic graduate level & \\
\hline
\end{tabular}

reduction in the duration of acid GER, which plays a relevant role in the development of GERD. Further larger evaluations are needed to eventually confirm these preliminary data.

\section{PO-0600 ASSESSMENT OF UNSUCCESSFULL MATERNAL BREASTFEEDING FACTORS IN FIRST DAY AFTER DELIVERY}

${ }^{1}$ A Mortazavi, ${ }^{2} \mathrm{M}$ Moharramnejadifard. ${ }^{1}$ Neonatal Ward, Social Security Organization, Zanjan, Iran; ${ }^{2}$ Rooming in Ward, Social Security Organization, Zanjan, Iran

\subsection{6/archdischild-2014-307384.1240}

Background and aims In this research we study the preventive factors in successful breastfeeding in first day after delivery.

Methods and materials This research type was observational descriptive case series. It takes from august 2013 to February 2014. Our target populations were 387 and contain every delivered mother with breastfeeding problems in first day after delivery. For every mother unsuccessful breastfeeding factors as table1 determined and data analysed with SPSS type 20 software and assessed with pearson's correlation and linear regression.

\begin{tabular}{llll}
\multicolumn{5}{l}{$\begin{array}{l}\text { Abstract PO-0600 Table } 2 \\
\text { factors influencing correlation }\end{array}$} \\
\multicolumn{5}{c}{ Standardised Coefficients } \\
confidence level & Sig. & (Beta) & causes \\
$100 \%$ & .000 & .400 & Newborn causes \\
$100 \%$ & .000 & .426 & Environment and Hospital causes \\
$100 \%$ & .000 & .744 & Maternal causes \\
$98.6 \%$ & .014 & -.064 & Cultural causes \\
$94.6 \%$ & .054 & .047 & Educational causes \\
$93 \%$ & .699 & -.009 & Epidemiologic causes \\
\hline
\end{tabular}

